Article

\title{
High-Grade Chemicals and Biofuels Produced from Marginal Lands Using an Integrated Approach of Alcoholic Fermentation and Pyrolysis of Sweet Sorghum Biomass Residues
}

\author{
Florin Nenciu ${ }^{1, *}$, Maria Paraschiv ${ }^{2, *}$ (D), Radu Kuncser ${ }^{3, *}$, Constantin Stan 4 , Diana Cocarta $4,5, *$ \\ and Valentin Nicolae Vladut 1
}

check for

updates

Citation: Nenciu, F.; Paraschiv, M.;

Kuncser, R.; Stan, C.; Cocarta, D.;

Vladut, V.N. High-Grade Chemicals and Biofuels Produced from

Marginal Lands Using an Integrated Approach of Alcoholic Fermentation and Pyrolysis of Sweet Sorghum

Biomass Residues. Sustainability 2022,

14, 402. https://doi.org/10.3390/

su14010402

Academic Editor: Paris Fokaides

Received: 9 November 2021

Accepted: 29 December 2021

Published: 31 December 2021

Publisher's Note: MDPI stays neutral with regard to jurisdictional claims in published maps and institutional affiliations.

Copyright: (c) 2021 by the authors Licensee MDPI, Basel, Switzerland. This article is an open access article distributed under the terms and conditions of the Creative Commons Attribution (CC BY) license (https:// creativecommons.org/licenses/by/ $4.0 /)$.
1 National Institute of Research-Development for Machines and Installations Designed for Agriculture and Food Industry-INMA Bucharest, 013811 Bucharest, Romania; vladut@inma.ro

2 Department Biomaterials \& Bioproducts, National Institute for Research and Development for Biological Sciences (INCDSB), 060031 Bucharest, Romania

3 National Research and Development Institute for Gas Turbines COMOTI, 061126 Bucharest, Romania

4 Faculty of Energy Engineering, University POLITEHNICA of Bucharest, 060042 Bucharest, Romania; cstan@upb.ro

5 Academy of Romanian Scientists, 030167 Bucharest, Romania

* Correspondence: florin.nenciu@inma.ro (F.N.); mariaparaschiv@gmail.com (M.P.); kuncser@gmail.com (R.K.); dianacocarta13@yahoo.com (D.C.)

\begin{abstract}
New global directions align agricultural land resources towards food production; therefore, marginal lands could provide opportunities for second-generation energy crops, assuming that in the difficult conditions of plant development, productivity can be maintained at relatively high levels. Sustainable bioenergy production on marginal lands represents an ambitious objective, offering highquality biofuels without competing with the agri-food industry, since it allows successful feedstock production to be performed on unmanaged areas. However, marginal land feedstock production generally shows several agronomic, techno-economic, and methodological challenges, leading to decreases in the obtained quantities of biomass and profitability. Sweet Sorghum is a technical plant that has the needed qualities to produce large amounts of biofuels on marginal lands. It is a high biomass- and sugar-yielding crop, characterized by a high photosynthetic efficiency and low fertilizer requirement, is resistant to drought, and adapts well to different climate areas. Marginal lands and contaminated soils provide a favorable development environment for plants such as sweet sorghum; however, in-depth research studies on biomass productivity must be carried out, as well as advanced quality evaluation of the products, in order to develop combined technologies that use resources efficiently. The present study starts with a comparative evaluation of two sweet sorghum crops established on both marginal and regular lands, assessing plant development characteristics and juice production, and an evaluation of bioethanol generation potential. The vegetal wastes resulting from the processing were treated by pyrolysis, with the aim of maximizing the productivity of high-quality liquid biofuels and chemicals. The charcoal obtained in the thermal processes was considered as an amendment of the soil so that marginal land quality could be improved over time.
\end{abstract}

Keywords: biomass pyrolysis; sweet sorghum crops; marginal soils; alternative energy

\section{Introduction}

\subsection{Context and the Importance of Developing the Field of Research}

Today we are facing many challenges and concerns associated with pollution, global warming, and natural resource depletion. Consequently, research is focusing on more sustainable development, especially regarding energy production. It is only a matter of time before the only existing sources for energy production are renewables, and new opportunities will be created for processing various non-recyclable waste, vegetal waste, and biomass. 
The mission to develop innovative, mature, and viable technologies that can sustainably convert biomass-based resources into high-quality biofuels and chemicals is not just an important stage in industrial development, but also a milestone for redesigning the world in a safer environment for future generations.

Global research objectives are aimed at including plant waste in the processes of producing efficient biofuels and overcoming difficulties related to biomass characteristics such as high moisture content, low calorific value, and increased loosening, or increased processing and transportation costs, making it difficult to successfully produce and use biofuels in large-scale applications [1,2].

The establishment of various intensive energy crops has long been considered an opportunity to reduce the widespread use of fossil fuels and chemicals. However, industrialscale cultivation of these crops is achieved to the detriment of food production and has proven to generate long-term environmental negative effects on the ecosystem, drastically reducing their expected benefits [3,4].

One possible approach to offset competition with food production would be to plant various crops with special characteristics and high potential for biomass production on marginal, contaminated, or nutrient-depleted lands, carefully analyzing aspects related to productivity and production cost. Particular attention must be paid to the conversion efficiency since the total biofuel costs on production and processing often ends up being higher than the cost of synthesizing petroleum fuels. Therefore, the technologies employed for planting, harvesting, transporting, and processing must produce qualitative biofuels or chemicals with special valuable applications $[5,6]$.

One energy crop suitable for planting on difficult soils is sweet sorghum (Sorghum bicolor (L.) Moench), because of its characteristics of easy adaptability in various climatic conditions, disease resistance, good biological productivity [7], and higher stress efficiency than other traditional crops. Sweet sorghum juice is rich in sugars and has a rich plant mass, and has significant potential to be used for chemicals and biofuel production [8].

A crop established on degraded or polluted soils cannot be used in human nutrition or to produce animal feed, and it is not considered a very advantageous factor in restoring soil quality, either. One of the preferred areas of use for this potentially contaminated biomass is the renewable fuel industry, after applying different types of heat treatments and processes that would increase its value.

Sweet sorghum juice obtained by pressing the stems can be subjected to a process of alcoholic fermentation and distillation to produce bioethanol [9], and the bagasse and the plant leaves resulting as waste from the process can be considered raw material for the pyrolysis process [10].

Integration into the agricultural use of degraded and contaminated soils to obtain highquality fuels that can be used in internal combustion engines, using both the juice obtained by pressing sweet sorghum stems in the production of bioethanol and the pyrolysis of plant mass to obtain bio-oils, is an extremely important direction both for environmental protection and for the transition from fossil fuels to renewable ones.

\subsection{Efficient Use of Marginal Lands for Food and Bioenergy Production}

The potential of marginal lands to enhance food security and promote bioenergy production has attracted a lot of attention. However, various environmental concerns, ecosystem service drawbacks, and long-term viability issues have been questioned in relation to the usage of marginal lands $[10,11]$. In Europe, agricultural marginal lands have been characterized as land uses that are on the edge of economic viability-areas where cost-effective production is not possible under the given site conditions, cultivation techniques, agricultural policies, or macro-economic conditions [12,13].

Marginal lands are therefore characterized by low productivity and reduced economic return, which might produce serious limitations for agricultural use $[14,15]$. These lands generally refer not only to low production, but also to several other limitations that make them unsuitable for agricultural practices and ecosystem function, such as low accessibility, 
soil erosion, the existence of ecologically sensitive areas, chemical contamination, the inability to carry out agricultural work, or easy floodability [16]. Some land limitations may not be directly associated with crop production, at least in the short term, but they might be considered marginal for biodiversity purposes. The USDA-NRCS made a classification of marginal lands according to some indicators of damage [17] associated with land suitability, considering that in most cases land limitations cause a reduction in agricultural value. Crops produced from marginal lands could be worth less than the total cost incurred for the agricultural works of establishing and harvesting, processing works, transport, or possible rents paid to have access to the respective area.

Classifications of marginal lands do not allow soil fertility potential to be evaluated. When considering the establishment of highly resistant cultures such as Miscanthus or different species of Sorghum, the real productivity of a marginal land can be quantified only in a practical way [18].

Cultivation of marginal lands is inevitable, considering the limitations related to quality farming land, which is critical in emerging countries due to rising food and energy demand [19]. According to some research studies [20], increasing food production would require the conversion of marginal areas to sustainable agricultural management methods, as well as the restoration of degraded soils and ecosystems. Therefore, the importance of identifying new ways of reintegrating marginal lands for agricultural production must be considered, in correlation with the need for land conservation and long-term viability. Heat treatments can also be used to process plants grown on contaminated and hazardous soils, where their use by incineration could cause serious health risks [21-23].

\subsection{The Current Situation of Technologies Used for Transforming Technical Plants into High-Quality Fuels and Chemicals}

There are several techniques commonly used for the thermal processing of agricultural waste. However, practical experiences have shown that using biomass as a fuel in largescale applications often raises difficulties because the material is bulky, has high humidity levels, and is highly dispersed. These shortcomings usually increase the production cost, making the processing operations financially unprofitable [24].

Thermo-chemical conversion of biomass includes processes such as gasification, slow pyrolysis, fast pyrolysis, hydro-carbonization, and combustion, which are characterized by differences in oxygen supply, retention time, temperature, and pressure variation. Because slow and rapid pyrolysis are feedstock-flexible possibilities, a variety of biomass sources have been investigated as suitable precursors, due to their reduced cost and availability [25]. A favorable approach involves obtaining higher-quality fuels using specific thermo-chemical techniques, and pyrolysis is the most intensely studied. Fast pyrolysis is a thermo-chemical conversion method used to produce mainly liquid fuel from biomass, based on thermal decomposition of organic compounds in the absence of oxygen [25,26]. Pyrolysis oils are compounds that are preferred as biofuels for their high calorific values, easy transportation and storage, low nitrogen and sulfur content, and the possibility of easy conversion into high-rated chemicals [27]. Efforts to turn renewable crop biomass into fundamental chemical elements that will be integrated into various common goods have been also intensified in recent years. However, a switch to bio-based polymers is dependent on the availability and consistency of important quantities of feedstock sold at reasonable prices. Commercializing a biobased polymer needs continuous, simultaneous progress in numerous research fields.

Another benefit of pyrolysis is the opportunity to use a wide variety of feedstock, which gives the system flexibility, which is a useful element for agricultural waste, especially when the raw material is not homogeneous.

To obtain products with high energy density and superior energy properties, the variation during thermal decomposition has to be considered and several factors have to be analyzed, such as temperature levels, operating pressures within the reactor, the residence 
time of the solid, the heating rate, the gaseous environment, the use of catalysts, and the initial properties of the biomass [28].

Pyrolysis of wastes generated from agriculture can be defined as the controlled decomposition of the organic vegetal mass matrix in the absence of an oxidizing agent, or in an amount so small that gasification does not occur completely, to obtain solid, liquid, and gas as byproducts. Oils obtained by pyrolysis are very valuable, because they can be upgraded by catalysts to produce refined fuels or can potentially be used as highly valuable chemicals $[29,30]$.

Biochar is another product obtained by the pyrolysis of sweet sorghum and is considered [31] an ecofriendly and multifunctional material with significant potential for the remediation of contaminated soils or in the framework of biochar-based water treatment systems. The physical and chemical properties of biochar, such as ash or mineral content, aromaticity, surface structures, $\mathrm{pH}$, and surface functional groups, are mostly determined by the feedstock that is used and the pyrolysis temperature. The alkalinity of biochar usually increases directly proportionally to the pyrolysis temperature [32], obtaining a higher alkalinity by processing the vegetal mass of the plants than by treating manure. The hydrologic properties of biochar are directly influenced by several aspects, such as the production processing method, the type of feedstock used, the particle size, or the wetting properties [33,34], being noted that biochar generated at higher temperatures $\left(400-600^{\circ} \mathrm{C}\right)$ was shown to have the best hydrologic qualities [35].

Another intensely studied direction $[36,37]$ is to process biomass in the presence of various catalysts in order to obtain a densification of the biomass, since the energy content can be improved this way. Although the densification technique is used more for combustion processes, the use of catalysts with a role in improving the quality of the obtained products, in association with the reduction of pollutants, is a frequently considered goal in the field of biomass processing.

The mechanical durability of solid fuels obtained in thermo-chemical reactions is the ability to remain as close as possible to the initial state over long time periods. It can be improved by reducing the content of lignin, fat, and other extractives found in the catalysts [38] and works in a complementary way with the variation of the reaction parameters [39]. However, in our research study, the objective was to obtain rather a very airy and low-density solid product. The solid product was used for the restoration of marginal soils; therefore, it needed to allow the bacteria and fungi to hide and grow. In addition, a supply of carbon and minerals was provided to the degraded soil, which helped to reduce the deterioration of arable soils by applying regenerative ecological technologies [40].

\subsection{General Aim and Scope of the Paper}

Considering sweet sorghum's characteristics of adaptability and the opportunity for cultivation on poor and contaminated soils, an experimental culture was established on marginal lands to evaluate the potential for producing both juice and biomass. The juice obtained by extraction with extruding equipment was subjected to maceration and double distillation, obtaining bioethanol.

The vegetable mass resulting as waste, composed of the bagasse, seeds, and leaves of the sweet sorghum plant, was subjected to pyrolysis treatment in conditions that maximized the production of high-quality bio-oils (tar). The bio-oil has the potential to be used for the production of high-value chemicals or biofuels.

The compounds obtained by pyrolysis were subsequently analyzed and characterized, with the treatment regime being varied and optimized, to obtain the maximum quantities of the compounds of interest.

Following pyrolysis, solid by-products were obtained in the form of a biochar. This product has a high potential to be used as an amendment to improve the quality of degraded soil where the sweet sorghum plantation was established, improving the land capability classification over time. 
To integrate marginal lands into the agricultural circuit, an approach designed to have beneficial effects on the ecosystem was assumed, stopping soil degradation processes and creating practical methods to improve the quality of fuels obtained from biomass waste. The general process diagram that illustrates the experimental activity described in the present paper is depicted in Figure 1.

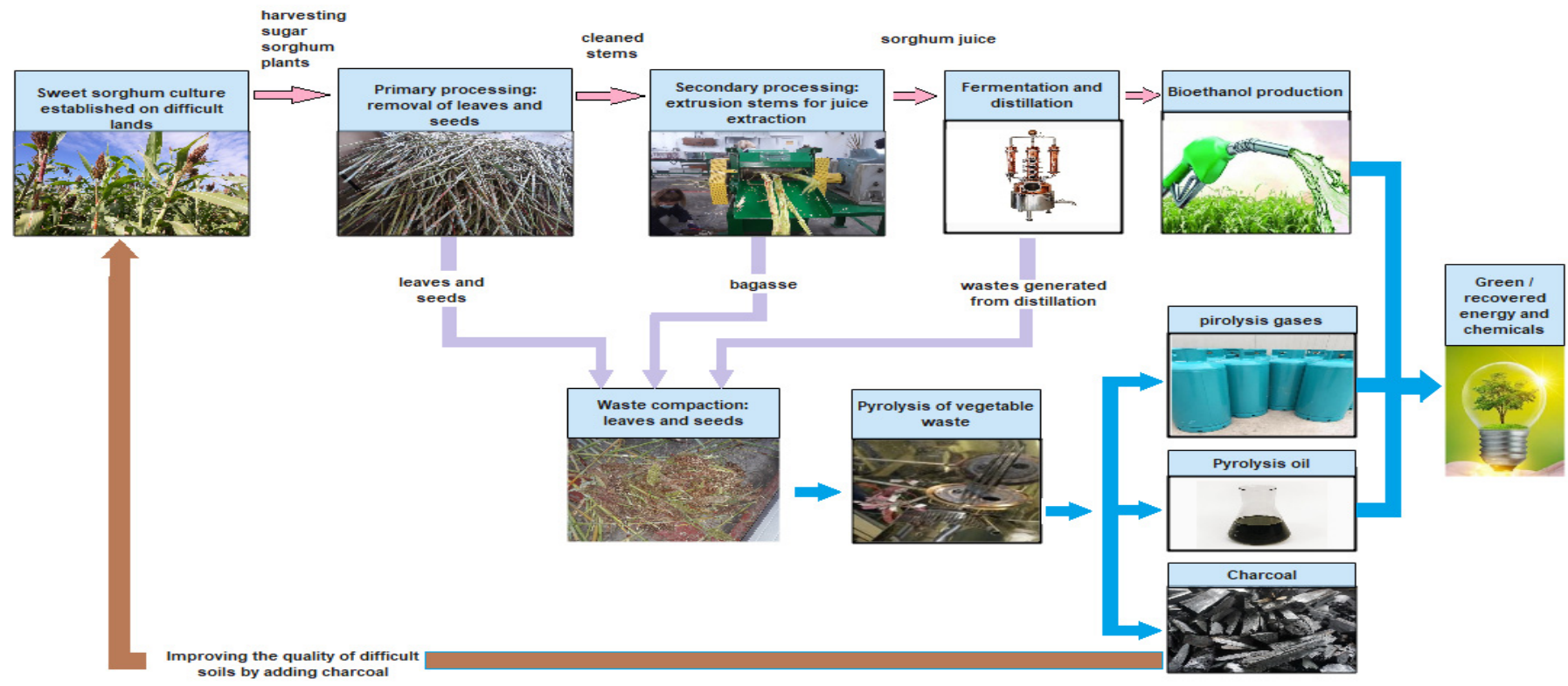

Figure 1. Experimental design of the research described within the current paper.

\section{Materials and Methods}

The experimental design comprised three main phases. The first phase dealt with assessing the productivity of the sweet sorghum crop when planted on marginal soils to evaluate the real output of biomass and juice, and the productivity of bioethanol obtained from sweet sorghum juice. The second phase envisaged the production and evaluation of the bio-oil product obtained by pyrolysis in relation to the thermo-chemical parameters. The third phase (which is not the subject of the current paper) involved evaluating the biochar's ability to recondition marginal lands. According to the land capability classification (LCC) derived from the USDA-NRCS (2010) [17], the marginal land analyzed was assigned to Class 6, with severe limitations that makes it generally unsuitable for cultivation and that restrict its use mainly to pasture, rangeland, forestland, or wildlife habitat.

Sweet sorghum tolerates drought and high-temperature stress better than many crops, but it does not grow well under low temperatures. Therefore, 15 May was chosen for the establishment of the culture, taking into account the local climatic specificities.

Sweet sorghum is an ideal candidate for difficult, contaminated, or marginal areas because it can be grown under reduced inputs (water, fertilizer) and responds more efficiently to stresses than other traditional crops. Therefore, after planting (performed according to the specifications of the seed producer), the crops were not irrigated and no additional treatments were applied. A locally resistant hybrid was tested in the experiment on two different areas (regular soil and marginal soil), each measuring 0.5 hectares. The main characteristics of the plant were stem thickness of $25-30 \mathrm{~mm}$ and height of $3.6-3.9 \mathrm{~m}$, increased leaf size, cellulose content of 35-38\%, amount of sugar in the juice of the stem of 14-19\%; tolerance to soil salinization, and resistance to diseases and pests.

To establish the growing characteristics for the plants raised on different soil types, 20 different perimeters of 1 square meter each were harvested and associated with each culture. For the assessment, the randomized complete block design was used. The leaves were removed from the stem, then the panicles with seeds and all the components were weighed separately. The sweet sorghum cleaned stems were extruded using dedicated 
equipment in order to obtain the juice, and the fiber resulting from the process (bagasse) was weighed and evaluated in terms of humidity. The extracted juice was evaluated in terms of soluble dry matter and Brix degree, using a professional Abbe digital Brix refractometer.

Weather variables did not differ considerably during the sweet sorghum growing period, since the plantations were established at a distance of $1 \mathrm{~km}$ from each other.

\subsection{Evaluation Phase of the Biomass Productivity Obtained from a Sweet Sorghum Crop and Planted on Marginal Lands (Degraded Soils)}

Two experimental crops were established on normal and marginal lands, and the same agricultural works were carried out according to the specifications of the seed producer and the norms of good practices. The planting operations were performed, keeping $15 \mathrm{~cm}$ between plants and $60 \mathrm{~cm}$ between rows, and weed growth was controlled by mechanical weeding. Harvesting of the sweet sorghum was performed using automatic threshing equipment, which cut the stem from $2 \mathrm{~cm}$ above the ground when the plant reached maturity, and was carried out only when the Brix index exceeded the value of 18 Brix degrees. The plants were then plucked for leaf removal and pressed with stem extrusion equipment, as showed in Figure 2.

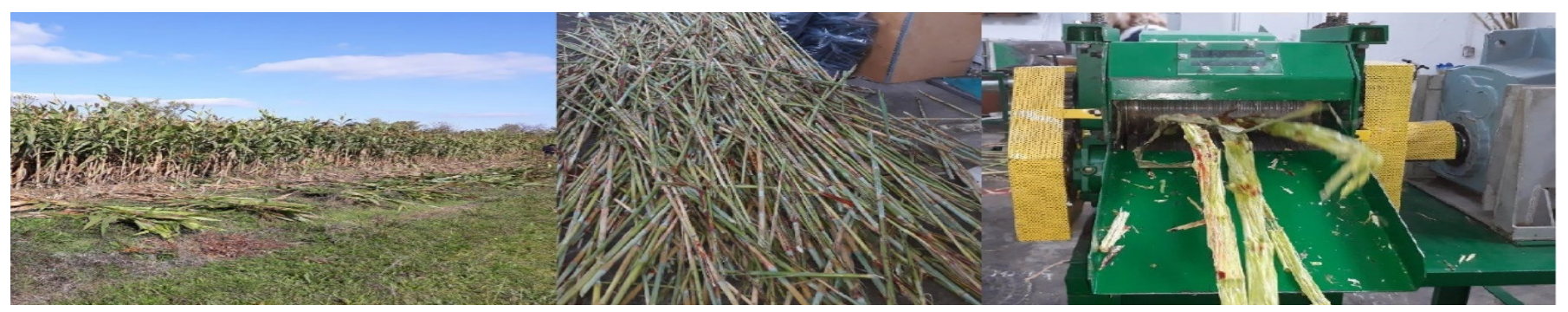

(a)

(b)

(c)

Figure 2. The main phases of sweet sorghum biomass processing: (a) the operation of threshing sweet sorghum plants, $2 \mathrm{~cm}$ above the ground; (b) the operation of removing leaves and seeds from sorghum stems; (c) the operation of extruding the sorghum stems to extract the juice.

Sweet sorghum productivity per hectare was evaluated by analyzing 20 perimeters of 1 square meter each for both cultures. In each perimeter the average plant dimensions (height and thickness), the vegetal mass of the plants grown per square meter, and the number of plants that managed to grow vigorously per square meter were determined. Then, each component of the plants (leaves, tops with seeds, and cleaned stems) was weighed separately for each representative area, and after extruding the stems, the juice and bagasse were weighed.

The obtained data allowed us to analyze the differences in productivity between the two crops, evaluating how the soil quality affects the production of juice and biomass. Knowing the amount of juice that can be obtained per hectare and measuring the Brix index with a professional refractometer ABBE KRUSS AR4, it was possible to determine the maximum amounts of sugars that can be obtained from the two crops of sweet sorghum, using Guigou et al. Equation (1), for the range of 12.2 to $18.6^{\circ}$ Brix [41].

$$
\text { Total sugar }(\mathrm{g} / \mathrm{L})=12.6 \times{ }^{\mathrm{o}} \text { Brix }-43.1(\mathrm{R} 2=0.96)
$$

Sweet sorghum harvesting for both crops was performed after the Brix index reached the value of $18{ }^{\circ}$ Brix; therefore, the refractometric analyses showed uniform values. Based on the sugar value found in the extracted juice, it was possible to determine the total amount of bioethanol obtained for the culture established in marginal soils in relation to the one established on regular soils. 
Considering an average sugar content in the juice of $110 \mathrm{~g} / \mathrm{L}$ and a theoretical yield of ethanol from sweet sorghum juice sugars of $0.51 \mathrm{~g}$ ethanol/g sugar, with an expected conversion ratio of $90 \%$, the potential for bioethanol production for the two cultures was calculated.

\subsection{Pyrolysis of Sweet Sorghum Vegetal Mass for Obtaining High-Quality Chemicals and Biofuels}

The main goal of performing the thermal processing of biomass was to obtain highly calorific liquid fuel using the pyrolysis process. Pyrolysis offers advantages over other product-processing methods, as the treatment that maximizes the production of bio-oil with superior technical applications and having the potential to be used to produce several highly valuable chemicals. The pyrolysis unit consists of a cylindrical reactor and a liquid phase-condensing system, as shown in Figure 3.

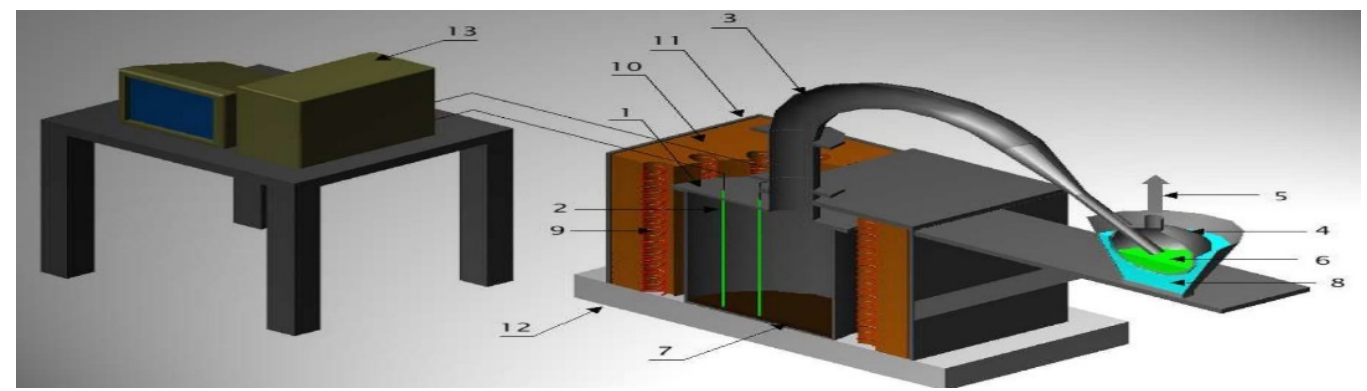

Figure 3. Diagram of the pyrolysis experimental setup: 1-installation reactor, 2 -thermocouples, 3-gas exhaust, 4-condensation system, 5-non-condensable gas exhaust, 6-liquid pyrolysis product, 7-solid phase, 8-ice, 9-electrical resistors, 10 and 12-insulating materials, 11-stainlesssteel protection, 13-automatic data acquisition system.

The main characteristics of the pyrolysis reactor used in the experiment are an inner diameter of $130 \mathrm{~mm}$, a height of $330 \mathrm{~mm}$, and a wall thickness of $2 \mathrm{~mm}$. The wall is heated by electrical resistors with a total power of $5 \mathrm{~kW}$, isolated with a thick layer from the outside environment. The maximum temperature that can be reached is $800{ }^{\circ} \mathrm{C}$. The experiments were performed at the decomposition temperatures identified by thermogravimetric analysis, between 350 and $600{ }^{\circ} \mathrm{C}$. The wall temperature is measured with an $\mathrm{N}$-type thermocouple and is maintained by a proportional-integral-derivative controller (PID controller).

The vapors obtained by heating are condensed by a refrigerant and collected in a calibrated glass container that is immersed in ice to further increase the condensation rate.

Two series of experiments were performed for each sample to verify the accuracy of the data. To be sure all the phases would be detected (the first vapors, the first condensation drops, the peak of the condensable gas release), temperature levels of 2-3 min were used, starting with $150{ }^{\circ} \mathrm{C}$ from 50 to $50^{\circ} \mathrm{C}$ and going up to a temperature of $500^{\circ} \mathrm{C}$. To obtain good-quality solid residue, the temperature of $500{ }^{\circ} \mathrm{C}$ was kept for $120 \mathrm{~min}$.

The main components of the pyrolysis experimental setup are depicted in Figure 4.

A mass of approximately $150 \mathrm{~g}$ of sample was introduced into the reactor without any process of crushing, drying, or pre-treatment, as shown in Figure 5. Sweet sorghum plants were analyzed both before extrusion and after extrusion (bagasse) to identify the differences in the production potential of valuable chemical components. To accurately simulate the industrial pyrolysis of the sweet sorghum plants, the stem, leaves, and seeds were taken in the reference sample in the same percentages as produced by the plant. 


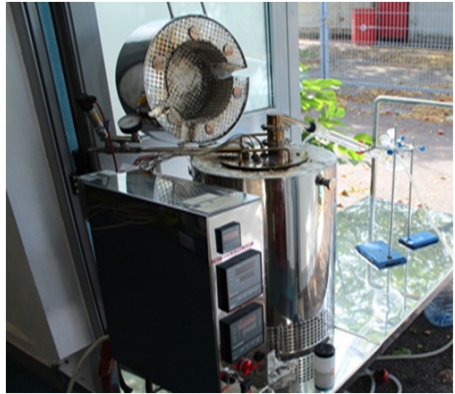

(a)

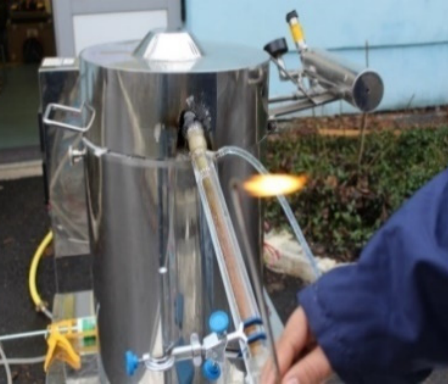

(b)

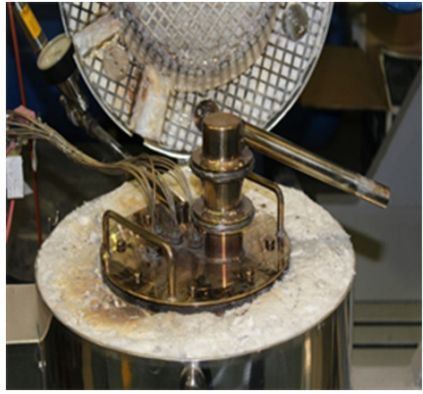

(c)

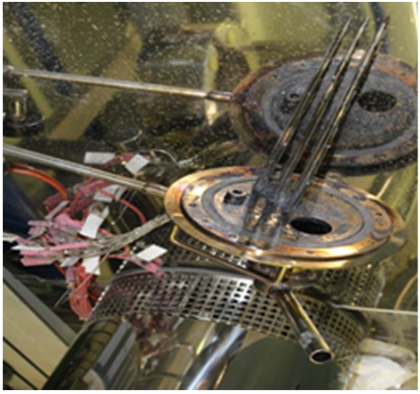

(d)

Figure 4. Pyrolysis experimental setup: (a) experimental pyrolysis installation for processing biomass; (b) gas condenser; (c) reactor and external insulation layers; (d) upper cover with thermocouples placed on levels.

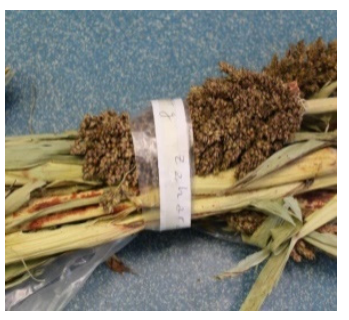

(a1)

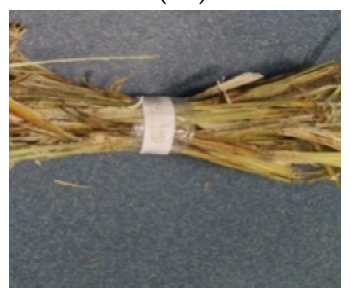

(a2)

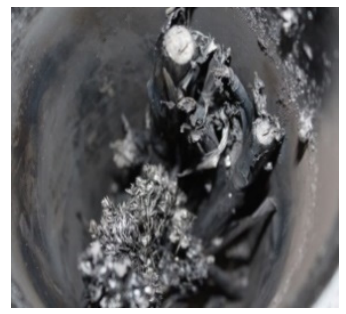

(b1)

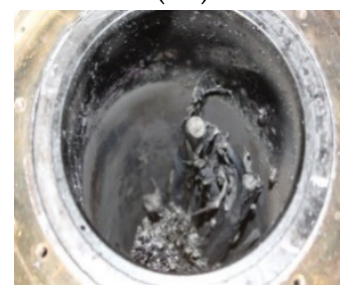

(b2)

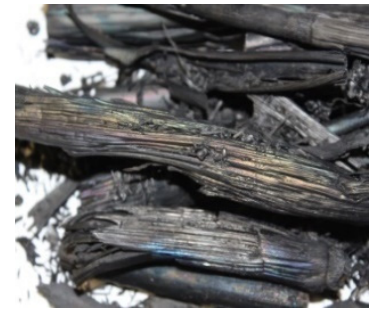

(c1)

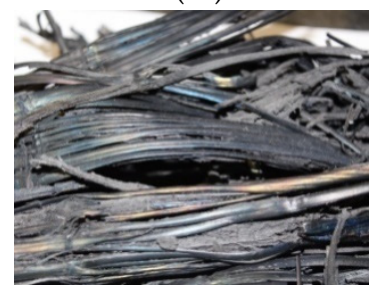

(c2)

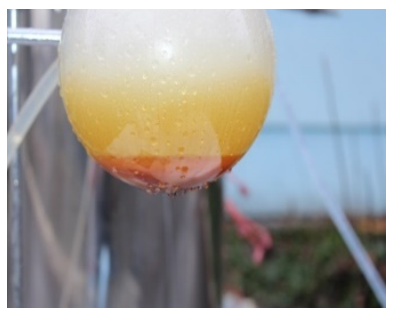

(d1)

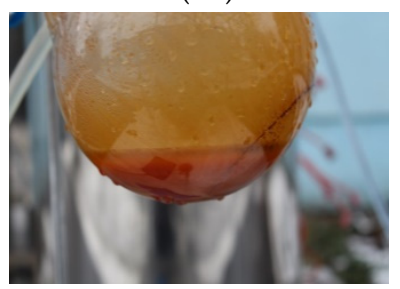

(d2)

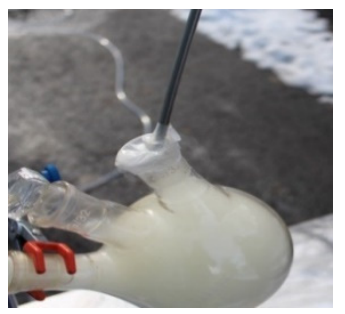

(e1)

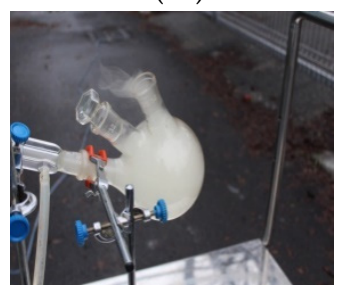

(e2)

Figure 5. Method used for the pyrolysis process of sweet sorghum plants before extrusion and the pyrolysis of bagasse after extrusion (after the juice has been extracted). Pictures (a1-e1) show the pyrolysis of sorghum stems before extrusion, whereas pictures (a2-e2) show the pyrolysis of the bagasse after juice extraction: (a) weighing the stems, leaves, and seeds and introduction of the sample to the reactor; (b) biochar obtained in the pyrolysis reactor; (c) overview of biochar special characteristics: high surface area ensures soil remediation applications, enhances microbial relationships, and contributes to soil nutrition improvement; (d) tar (bio-oil) obtained from pyrolysis, containing the condensed gases; (e) non-condensable gases obtained by pyrolysis.

\subsection{Materials and Methods-Analysis and Characterization of Liquid and Solid Fuels Obtained from the Pyrolysis Process}

The most important parameters affecting the generation of pyrolysis products are the pyrolizer design, biomass composition, and operating parameters such as heating rate, pyrolysis temperature, residence time in the reaction, and particle size of the substrate. Based on heating rate, pyrolysis can be classified as slow (heating rate of $0.1-0.8^{\circ} \mathrm{C} / \mathrm{s}$ ) or fast (heating rate of $10-200{ }^{\circ} \mathrm{C} / \mathrm{s}$ ).

Thermogravimetric analysis was performed using thermogravimetric analyzer Setaram SETSYS Evolution TGA-DTG/DSC. Small pieces of $7 \mathrm{mg}$ from each sample were pyrolyzed under a $20 \mathrm{~mL} / \mathrm{min} \mathrm{N}_{2}$ flow at a $20{ }^{\circ} \mathrm{C} / \mathrm{min}$ heating rate, with the temperature varying from 50 to $600{ }^{\circ} \mathrm{C}$. The nitrogen flow rate ensured an inert atmosphere during functioning. 
The liquid fractions (bio-oils) were analyzed using gas chromatography with flameionized detector (FID), using a PERKIN ELMER XL Gas Chromatograph with Autosampler. The tar (bio-oil) was filtered using a glass filter for microsyringe (Filtstar GF) in order to remove impurities from the pyrolysis oil. Extraction and dilution of the components were performed using n-hexane as a solvent with a dilution of 1:50, stirring for 2 min with a shaker Vortex Velp-RX3. The sample was automatically introduced into the GC-MS using the autosampler. The column was VARIAN WCOT Fused Silica type (30 m length $\times 0.39 \mathrm{~mm}$ interior diameter, film thickness $0.25 \mathrm{~mm}$ ). The injector temperature was $250{ }^{\circ} \mathrm{C}$. The chromatograph program comprised $1 \mathrm{~min}$ at $45^{\circ} \mathrm{C}$ followed by a ramp to $300{ }^{\circ} \mathrm{C}$ at a rate of $7^{\circ} \mathrm{C} \mathrm{min}{ }^{-1}$. The final temperature was held constant for $10 \mathrm{~min}$. The equipment design allowed the split of the carrier gas flow to perform analyses using FID and MS detectors simultaneously. The mass spectrometer was operated at an electron impact ionization energy of $70 \mathrm{eV}$. The scan range was 30-450 m/ $\mathrm{z}$ and the individual compounds were identified from the GC/MS chromatograms using Library MS NIST [42].

\section{Results}

\subsection{Biomass Productivity and Evaluation of Bioethanol Production from Sorghum Juice}

Sweet sorghum planted on marginal soils (experimental culture established on $0.5 \mathrm{ha}$ ) showed good adaptability and an increased resistance to marginal lands (floodable and clayey soils), developing vegetal mass even in severe development conditions. The productivity on the marginal lands was lower, as can be seen in Table 1 . However, it should be mentioned that on the investigated marginal land many experimental crops had been established in the past, but they did not manage to reach maturity or had very small productions. Table 1 summarizes the data obtained for the two crops established on marginal soils and on regular soils.

Table 1. Comparative analysis of two sweet sorghum crops, established in the same planting and harvesting conditions, one being established on marginal soil and the other on regular soil.

\begin{tabular}{|c|c|c|c|c|}
\hline & Parameter & Unit & $\begin{array}{l}\text { Sweet Sorghum Culture } \\
\text { Established on } \\
\text { Marginal Soils }\end{array}$ & $\begin{array}{c}\text { Sweet Sorghum Culture } \\
\text { Established on } \\
\text { Regular Soils }\end{array}$ \\
\hline \multirow{3}{*}{ Plant characteristics } & $\begin{array}{l}\text { Number of sweet sorghum } \\
\text { plants per square meter }\end{array}$ & $\begin{array}{l}\text { plants per } \\
\text { square meter }\end{array}$ & $15-19$ & $19-21$ \\
\hline & Average diameter of plants & $\mathrm{mm}$ & 14.76 & 19.11 \\
\hline & Average plant height & $\mathrm{m}$ & 2.6 & 3.3 \\
\hline \multirow{8}{*}{$\begin{array}{l}\text { Quantities } \\
\text { obtained per } \\
\text { hectare }\end{array}$} & $\begin{array}{l}\text { Total plant fresh mass } \\
\text { harvested per hectare }\end{array}$ & t/ha & 31.2 & 49.2 \\
\hline & $\begin{array}{l}\text { Total plant dry biomass per } \\
\text { hectare }\end{array}$ & t/ha & 14.7 & 23.6 \\
\hline & Leaves & t/ha & 6.5 & 11.1 \\
\hline & Plant top with seeds & $\mathrm{t} / \mathrm{ha}$ & 2.4 & 3 \\
\hline & $\begin{array}{c}\text { Stem mass after removal of } \\
\text { leaves and tips }\end{array}$ & t/ha & 22.3 & 35.1 \\
\hline & Bagasse after stem extrusion & t/ha & 14.2 & 22.2 \\
\hline & Sorghum juice produced & $\mathrm{kl} / \mathrm{ha}$ & 8.1 & 12.9 \\
\hline & Seed mass & $\mathrm{t} / \mathrm{ha}$ & 0.6 & 0.5 \\
\hline \multirow{2}{*}{$\begin{array}{c}\text { Juice and } \\
\text { bagasse analysis }\end{array}$} & Average Brix at harvesting & Brix degree & 19 & 19 \\
\hline & Moisture bagasse & $\%$ & 47 & 48 \\
\hline
\end{tabular}


Table 1. Cont.

\begin{tabular}{|c|c|c|c|c|}
\hline & Parameter & Unit & $\begin{array}{c}\text { Sweet Sorghum Culture } \\
\text { Established on } \\
\text { Marginal Soils }\end{array}$ & $\begin{array}{c}\text { Sweet Sorghum Culture } \\
\text { Established on } \\
\text { Regular Soils }\end{array}$ \\
\hline \multirow{6}{*}{$\begin{array}{l}\text { Percentage } \\
\text { calculation }\end{array}$} & Sorghum juice & $\%$ & 25 & 26 \\
\hline & Bagasse & $\%$ & 50 & 45 \\
\hline & Plant top with seeds & $\%$ & 7 & 6 \\
\hline & Leaves & $\%$ & 18 & 23 \\
\hline & $\begin{array}{c}\text { Percentage of juice reported } \\
\text { to the processed stems } \\
\text { (without leaves, tips, } \\
\text { and signs) }\end{array}$ & $\%$ & 36 & 37 \\
\hline & $\begin{array}{l}\text { Percentage of bagasse } \\
\text { reported to the processed } \\
\text { stems (without leaves, tips, } \\
\text { and signs) }\end{array}$ & $\%$ & 62 & 63 \\
\hline $\begin{array}{l}\text { Bioethanol } \\
\text { production }\end{array}$ & $\begin{array}{l}\text { Bioethanol potential } \\
\text { (juice fermentation) }\end{array}$ & t/ha & 0.41 & 0.65 \\
\hline
\end{tabular}

Figure 6 comparatively evaluates the productivity in three growing conditions of sweet sorghum crops: (a) optimal planting conditions (theoretical data according to the information provided by the seed producer), (b) planting the crop on fertile soil but without adding nutrients and without irrigation, and (c) crop established on marginal land without adding nutrients and without irrigation. It can be observed that on fertile land without the use of irrigation or nutrient addition systems, a yield of $65 \%$ was obtained relative to the maximum theoretical value of the hybrid, whereas on marginal land the production was recorded at a value of $40 \%$.

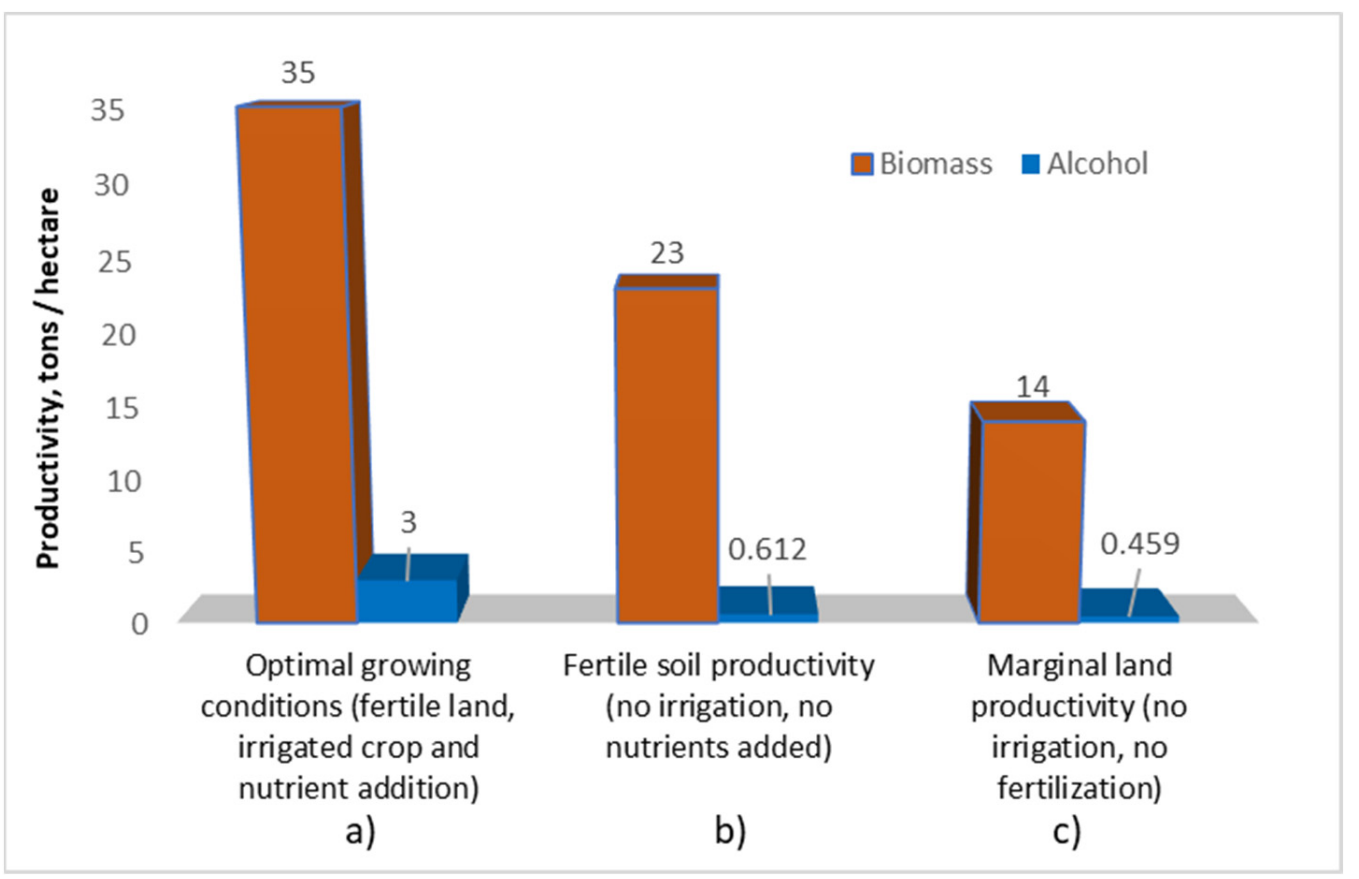

Figure 6. Comparative evaluation of sweet sorghum biomass and alcohol production, considering three planting conditions: (a) optimal growing conditions (fertile land, irrigated crop, and nutrient addition); (b) fertile soil productivity (no irrigation, no nutrients added); and (c) marginal land productivity (no irrigation, no fertilization). 
The bioethanol potential obtained exclusively by fermentation of the juice (where no procedures for converting plant mass to sugars using enzymatic or acid hydrolysis were used) was evaluated to be $0.45 \mathrm{t} /$ ha for the crop established on marginal soils and $0.61 \mathrm{t} / \mathrm{ha}$ for the crop established on regular soils.

The biomass wastes resulting from the bioethanol production consisted of the plant tops with seeds, leaves, and bagasse, and were subject to pyrolysis.

\subsection{Chemicals and Fuels Resulting from the Pyrolysis Process}

The decomposition reactions were begun in the range of $130-150{ }^{\circ} \mathrm{C}$ with a slight release of vapors, and the peak was reached around a temperature of $320-350{ }^{\circ} \mathrm{C}$, with a release of flammable liquid and non-condensable gases.

In terms of production percentages, the ratio of products obtained from sweet sorghum bagasse after extrusion (Figure 7a) and from sweet sorghum biomass that did not go through the extrusion process (Figure $7 \mathrm{~b}$ ) shows that a better bio-oil production can be obtained by processing sorghum bagasse; therefore, extrusion for juice removal can be considered a pre-processing phase for pyrolysis.

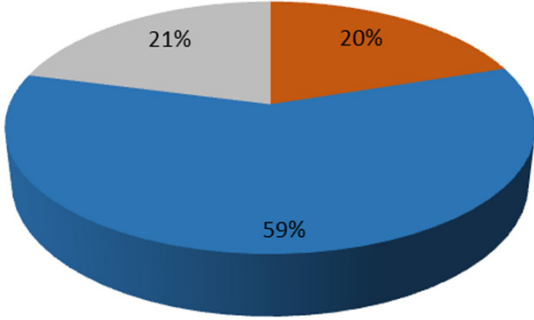

(a)

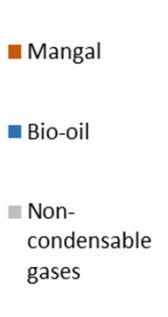

ases
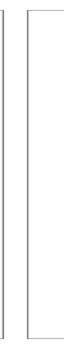

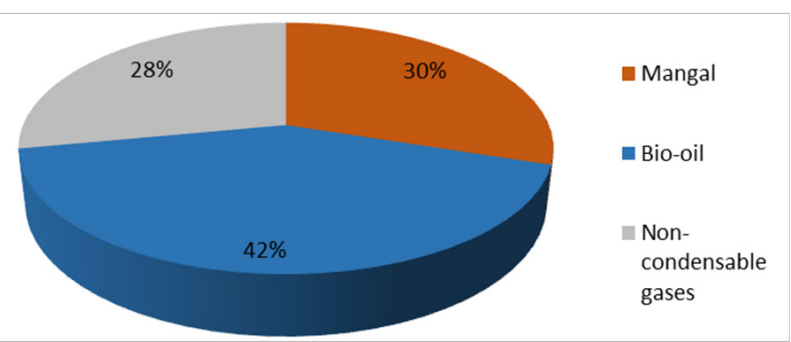

(b)

Figure 7. Products obtained from the pyrolysis of sweet sorghum biomass, calculated as percentage of total harvested mass: (a) sweet sorghum biomass processing; (b) sweet sorghum bagasse processing.

\subsection{Analysis and Characterization of Liquid Compounds Resulting from the Pyrolysis Process}

Pyrolysis is the thermochemical degradation of biomass into a variety of useful products such as tar, biochar (mangal), and combustible gases in an inert environment. Tar is a mixture of complex hydrocarbons containing substantial quantities of oxygen and water, formed as the result of the depolymerization and fragmentation of biomass, whereas biochar is formed because of cracking reactions and contains mainly carbon, with some hydrogen, oxygen, and inorganic ash.

Before conducting the pyrolysis process in the reactor, a preliminary analysis was performed using thermogravimetry techniques. The behavior of the thermal conversion of different types of lignocellulosic biomass was obtained by using two thermal assessment tools: thermogravimetric analysis (TG) and derivative thermogravimetry (DTG). For a better evaluation of the thermochemical degradation, the assessment was performed both for the core of the plant and for its outer shell. Our expectations were that the outer shell would contain more lignin, and the decomposition temperatures would be different (higher temperatures and longer decomposition periods).

Figure 8 depicts the weight loss curves (TG) and derivative of weight loss (DTG) for bagasse stem core (Figure 8a) and bagasse stem shell (Figure 8b), whereas Figure 9 depicts the same parameters for sweet sorghum stem core without extrusion (Figure 9a) and sweet sorghum stem shell without extrusion (Figure 9b). 


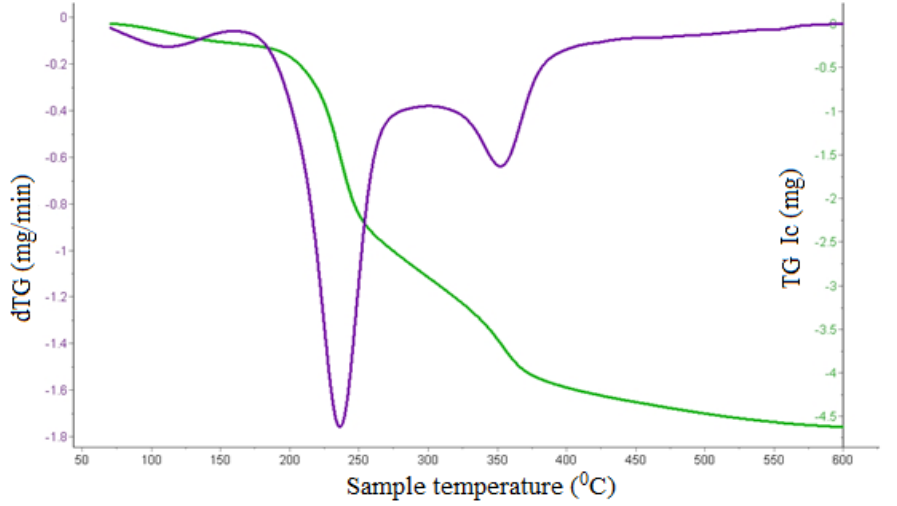

(a)

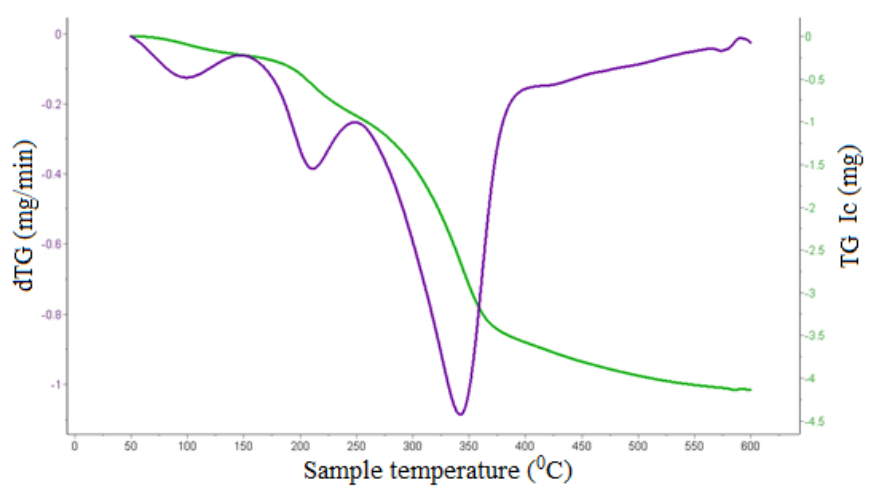

(b)

Figure 8. Thermogravimetric analysis of sweet sorghum bagasse: (a) weight loss curves (TG) and derivative of weight loss (DTG) for bagasse stem core; (b) weight loss curves (TG) and derivative of weight loss (DTG) for bagasse stem shell.

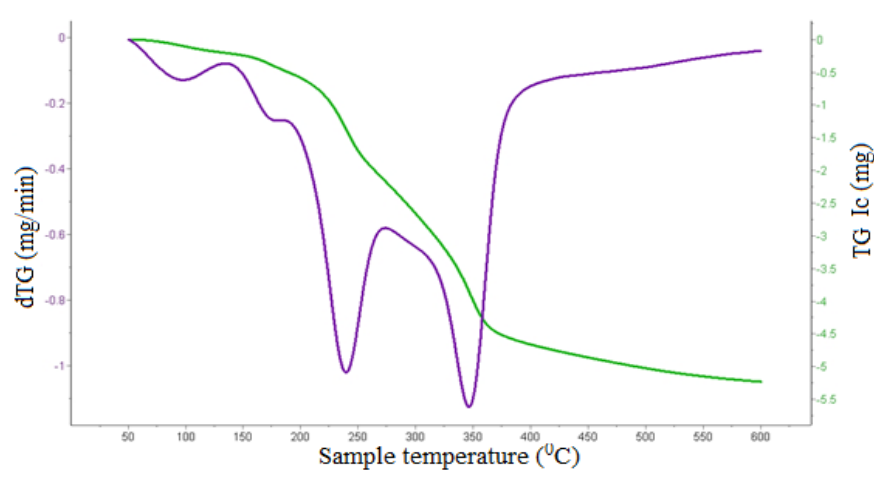

(a)

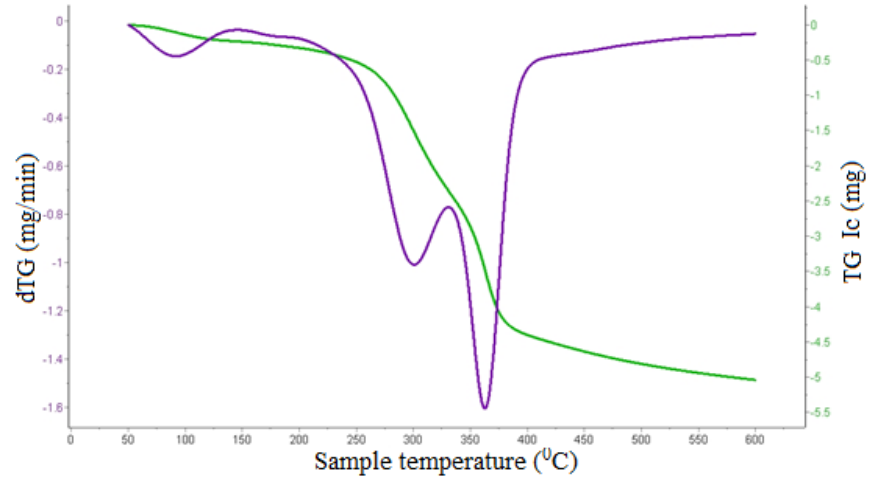

(b)

Figure 9. Thermogravimetric analysis of sweet sorghum plants: (a) weight loss curves (TG) and derivative of weight loss (DTG) for sweet sorghum stem core; (b) weight loss curves (TG) and derivative of weight loss (DTG) for sweet sorghum stem shell.

The DTG lines (purple color) depicted in Figures 8 and 9 show that the reactions occurring in the given temperature ranges were grouped together into two main lumps, identified by the deconvolution of the derivative thermogravimetry (DTG) curves corresponding to biomass compositions (hemicellulose, cellulose, and lignin). Green lines measure the percentage of mass loss with respect to temperature and time and demonstrate the thermal decomposition behavior during pyrolysis (TG). TG and kinetics of organic matter degradation during pyrolysis can help with planning and developing the pyrolysis process on an industrial scale.

Biomass pyrolysis is divided into the following main stages: Under $200{ }^{\circ} \mathrm{C}$ the removal of moisture takes place, in the temperature range of $200-450{ }^{\circ} \mathrm{C}$ the cellulose and hemicellulose of the analyzed sample decompose, and from $455^{\circ} \mathrm{C}$ to $1000{ }^{\circ} \mathrm{C}$ lignin is thermally degraded. Starting from the temperature of $600{ }^{\circ} \mathrm{C}$, the reduction in the decomposition reaction takes place, with char being oxidated to ash.

As expected, due to the structure, biomass degradation appeared to be a two-step process (two degradation peaks). In Figure 8a (bagasse stem core) and Figure 9a (sweet sorghum stem core) the first reversed peak was much bigger than the second reversed peak (purple lines), associated with a much higher amount of hemicellulose. In the case of our process parameter configuration, hemicellulose decomposed in the interval of $190-255^{\circ} \mathrm{C}$. The smaller peaks were associated with cellulose that covered the range of $300-400{ }^{\circ} \mathrm{C}$, with the highest decomposition rate at $350{ }^{\circ} \mathrm{C}$. We expected the two peaks to contain a part 
of lignin, which during rapid decomposition can degrade much faster; however, lignin degradation was better highlighted above $400^{\circ} \mathrm{C}$, in the form of a tail that decreased slightly towards $550{ }^{\circ} \mathrm{C}$.

Figure $8 \mathrm{~b}$ (bagasse stem shell) and Figure $9 \mathrm{~b}$ (sweet sorghum stem shell) depict a shift in the size of the two reversed peaks (purple line), given that the outer shell of the plant contained more cellulose and especially lignin. The degradation phase of hemicellulose took place in the interval of $150-250{ }^{\circ} \mathrm{C}$, whereas cellulose covered the range of $250-400{ }^{\circ} \mathrm{C}$, with both processes starting at lower temperatures than in the previous case. As in the previous case, there was a more intense degradation of lignin after the temperature of $400{ }^{\circ} \mathrm{C}$, with the observation that the amount was much higher in this situation.

Weight loss correlated with temperature (green line) determined the amount of mass loss rate as a function of temperature and time, confirming the hypotheses stated earlier and helping to program the parameters of the pyrolysis process and to identify the main substances evidenced in the samples.

The main information on the temperatures in the tested waste thermochemical decomposition is summarized in Table 2.

Table 2. Thermal and weight loss information on sample decomposition.

\begin{tabular}{cccccc}
\hline No. & Material & $\mathbf{T i}\left({ }^{\circ} \mathbf{C}\right)$ & $\operatorname{Tmax}\left({ }^{\circ} \mathbf{C}\right)$ & Tf $\left({ }^{\circ} \mathbf{C}\right)$ & Weight Loss $(\%)$ \\
\hline 1 & Bagasse stem core & 150 & 240 & 550 & 72 \\
\hline 2 & Bagasse stem shell & 150 & 280 & 550 & 68 \\
\hline 3 & $\begin{array}{c}\text { Stem core } \\
\text { (without extrusion) }\end{array}$ & 150 & 250 & 550 & 70 \\
\hline 4 & $\begin{array}{c}\text { Stem shell } \\
\text { (without extrusion) }\end{array}$ & 200 & 320 & 550 & 71 \\
\hline
\end{tabular}

Results show closed values for the temperature corresponding to the maximum rate for sweet sorghum stem core and bagasse stem core in terms of thermal degradation (Tmax). Despite the delay registered at the beginning, the process appeared to evolve faster. Concerning the weight loss, overlapping TG curves recorded small differences, identified at the beginning of the process. However, they had similar trends that indicate close thermochemical behaviors. The conversion rate of pyrolysis took place in a range between 68 and $72 \%$.

One of the specific features of our experiment is that the plants were introduced into the bioreactor during pyrolysis, without prior pretreatment. In addition, the real percentage rates of sweet sorghum elements (stem, leaves, seeds) were added to the sample subjected to processing to simulate, as accurately as possible, the industrial processing mode (where the vegetable mass will be introduced and mixed in the reactor). We aimed to maximize the amount and quality of tar; therefore, a fast pyrolysis process was used. Tar has the potential to produce the most expensive potential components for use in the chemical industry and for the production of high-value biofuels. Figure 10 shows a comparative evaluation of the tar produced by pyrolysis for both the sweet sorghum plant (green line) and the sweet sorghum bagasse (red line).

In Figure 10 it can be observed that the same major chemical compounds were in the two samples; the only difference was the quantity. A better rendering of the main constituents of the pyrolysis oil obtained from the two samples can be seen in Figure 11, where the main chemical compounds that were obtained are colored differently. 


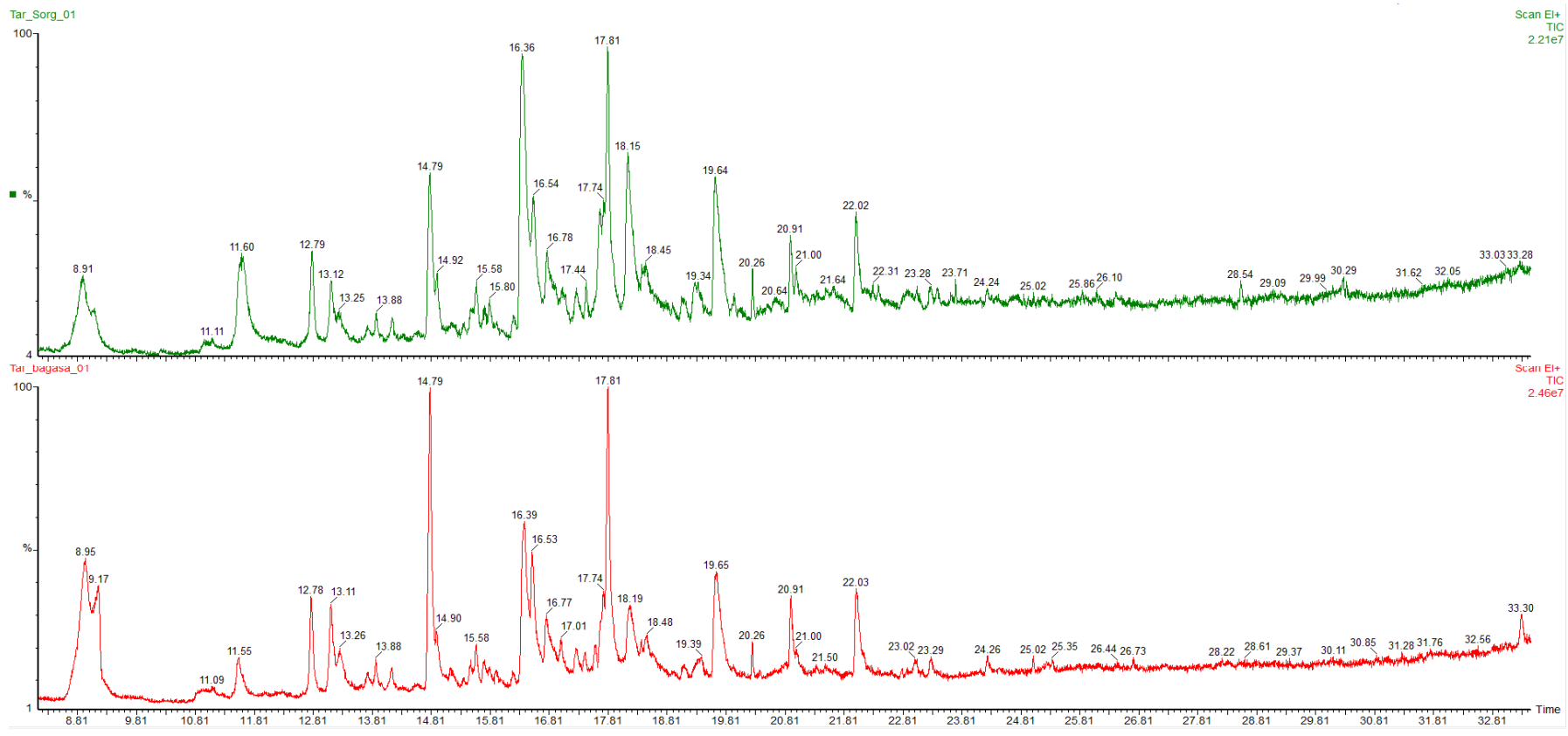

Figure 10. The chromatogram of the two bio-oils obtained from the pyrolysis process of the sorghum stems (green color) and of the bagasse obtained by extruding the sorghum stems (red color).

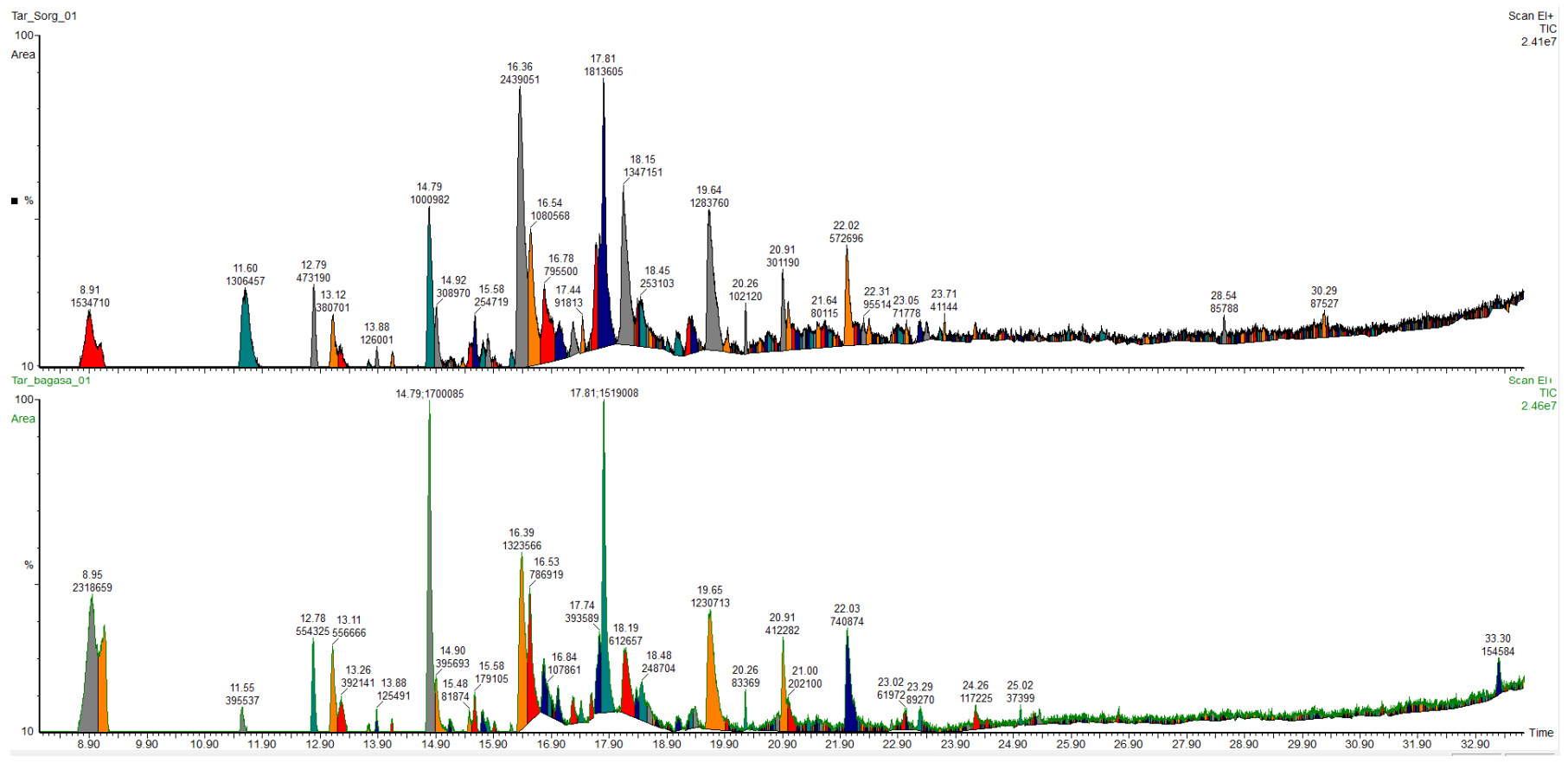

Figure 11. Main components identified in tar (bio-oil) obtained in the pyrolysis for sweet sorghum stems and bagasse.

The major compounds that were obtained in the bio-oil using the pyrolysis process are presented in Table 3. The mass spectrometer match ranged between 800 and 950 and the reverse match ranged between 790 and 900 . 
Table 3. Major compounds identified within the GC-MS analysis in the pyrolysis bio-oil (tar).

\begin{tabular}{|c|c|c|c|c|}
\hline $\begin{array}{l}\text { Retention Time } \\
\text { (min) }\end{array}$ & Compound & Name of Compound & Formula & $\begin{array}{l}\text { Molar } \\
\text { Weight }\end{array}$ \\
\hline 8.95 & & 2,5 dimethylfurane & $\mathrm{C} 6 \mathrm{H} 8 \mathrm{O}$ & 96 \\
\hline 11.55 & & Acetol acetate & $\mathrm{C} 5 \mathrm{H} 8 \mathrm{O} 3$ & 116 \\
\hline 12.78 & & $\begin{array}{l}\text { 2-methyl-2- } \\
\text { cyclopentenone }\end{array}$ & $\mathrm{C} 6 \mathrm{H} 8 \mathrm{O}$ & 96 \\
\hline 13.11 & & Acetylfuran & $\mathrm{C} 6 \mathrm{H} 6 \mathrm{O} 2$ & 110 \\
\hline 14.80 & & 2-furaldehyde, 5-methyl- & $\mathrm{C} 6 \mathrm{H} 6 \mathrm{O} 2$ & 110 \\
\hline 16.39 & & Phenol & $\mathrm{C} 6 \mathrm{H} 6 \mathrm{O}$ & 94 \\
\hline 17.81 & & Phenol, 2-methoxy- & $\mathrm{C} 7 \mathrm{H} 8 \mathrm{O} 2$ & 124 \\
\hline 18.15 & & m-cresol & $\mathrm{C} 7 \mathrm{H} 8 \mathrm{O}$ & 108 \\
\hline 19.63 & & m-ethylphenol & $\mathrm{C} 8 \mathrm{H} 10 \mathrm{O}$ & 122 \\
\hline 20.26 & & $\begin{array}{c}\text { 1-butoxy- } \\
\text { 1isobutoxy- butane }\end{array}$ & $\mathrm{C} 12 \mathrm{H} 26 \mathrm{O} 2$ & 202 \\
\hline 20.91 & & $\begin{array}{l}\text { Phenol, 4-ethyl } \\
\text {-2-methoxy- }\end{array}$ & $\mathrm{C} 9 \mathrm{H} 12 \mathrm{O} 2$ & 152 \\
\hline 22.03 & & Phenol, -2,6 -dimethoxy- & $\mathrm{C} 8 \mathrm{H} 10 \mathrm{O} 3$ & 154 \\
\hline 33.30 & & $\begin{array}{c}\text { p-cresol, } \\
\text { 2,2'-methylenebis } \\
\text { [6-tert-butyl }\end{array}$ & $\mathrm{C} 23 \mathrm{H} 32 \mathrm{O} 2$ & 340 \\
\hline
\end{tabular}

\section{Discussion}

Crop production on marginal lands is limited by the lack of infrastructure (considering that the lands can be located in inaccessible areas) and reduced soil fertility, resulting in higher costs for production than in typical crops.

Sweet sorghum cultivation on marginal lands has proven to record an acceptable level of productivity, given the difficult growing conditions (floodable and clayey soils). Establishing plantations on marginal lands characterized by low productivity for common 
crops may be an opportunity for sweet sorghum, as it can reintegrate some lands into the agricultural circuit. The development of the plants took place in good conditions, without carrying out expensive works such as irrigation, the addition of nutrients, or chemical treatment against weeds and diseases.

Regarding the biomass productivity obtained by sweet sorghum (Sorghum bicolor [L.] Moench) crops in other studies, substantial differences have been reported in the literature, depending on the climate, the type of soil, and the agricultural works applied, with a major impact being produced by irrigation and fertilizer application. Some of the hybrids offered productivity of dry biomass between 18.65 and $19.01 \mathrm{t}^{-1}$ [43], whereas the crops grown in a sub-humid climate and on saline land registered $12.2 \mathrm{t} \mathrm{ha}^{-1}$ biomass and $3425 \mathrm{~L} \mathrm{ha}^{-1}$ theoretical ethanol production. A semi-arid climate and wasteland offered a productivity of $8.6 \mathrm{t} \mathrm{ha}^{-1}$ biomass and $2091 \mathrm{~L} \mathrm{ha}^{-1}$ of alcohol [44], whereas irrigated and intensively treated and processed crops exceeded values of $35 \mathrm{t}$ ha ${ }^{-1}$ of dry biomass [45]. Comparing to the values obtained in the literature, the studied marginal land registered acceptable productivity values of $14.7 \mathrm{t} \mathrm{ha}^{-1}$ dry biomass per hectare without applying expensive works such as irrigation or adding fertilizers. In these conditions the productivity reached $40 \%$ from the theoretical values; however, it should be noted that Romania's warm climate with rainy springs offers benefits to sweet sorghum crops. The plantation was able to control weeds naturally (without the need for herbicide) due to the high growth of the plants. Plant pests were identified on the crops, the most important pest being from the aphid family, but they did not affect the economic damage threshold. However, the natural enemy of aphids, Coccinella septempunctata, managed to keep the pest population under control naturally; therefore, the use of insecticides is not recommended for the cultivation of sweet sorghum on marginal lands [46].

In addition, the application of biochar obtained by biomass pyrolysis on marginal lands can lead to quality improvement, given the high remedial properties of biochar.

However, a balanced attitude is needed in the use of marginal lands, given that some areas may raise concerns related to environmental impacts, ecosystem services, and sustainability. It is known that marginal lands can host some species of flora and fauna that would disappear due to intensive agriculture $[47,48]$.

The biomass production on the marginal lands was rated to $40 \%$ of the production registered on optimal planting conditions of the envisaged hybrid. Analysis of the level of plant growth per square meter showed similar values regarding the biomass produced from the two crops, except that on the marginal lands the plants were smaller and thinner, and therefore had higher lignin content [49].

The approach proposed in this paper to extract sweet sorghum juice to produce bioethanol by alcoholic fermentation and then use the vegetable waste obtained in the pyrolysis process for the manufacture of valuable chemical components (bio-oil), as well as an amendment for soil reconditioning (biochar), could bring benefits both financially and to the environment.

During thermal decomposition of the biomass under limited supply of oxygen and a temperature regime of up to $600{ }^{\circ} \mathrm{C}$, the material underwent a series of fragmentation reactions as volatile matter evolved, resulting in the generation of tar (bio-oil) and bio-char.

The compounds identified in the largest amounts in bio-oil can be used in a wide variety of purposes, such as the synthesis of fine chemicals and pharmaceuticals (Acetylfuran-); inhibitors and flavoring agents (2-furaldehyde, 5-methyl-); the production of bactericides, disinfectants, or herbicides (phenol); use in the food industry to provide flavor to beverages such as whiskey and coffee (phenol, 2-methoxy-); pesticides such as fenitrothion and fenthion, synthetic vitamin E, antiseptics, and preservatives (m-cresol); the production of food supplements (1-butoxy-1isobutoxy- butane); and adhesives and sealants, lubricants, and hydraulic fluids (phenol, 4-ethyl-2-methoxy).

The resulting biochar was a porous high-carbon product mainly composed of aromatic compounds. Due to the high porosity and adsorption properties, biochar is generally recognized for its soil reconditioning efficiency, and it may be further improved or trans- 
formed into activated carbon by physical or chemical activation. It is important to note that the application of biochar on the marginal lands enhances microbial relationships, adds concentrated mineral content, and contributes to surface functional groups, which helps to restore the productive upper soil layers.

It was determined that in the pyrolysis treatment, bagasse can produce bio-oil more qualitatively than unprocessed sorghum stem, because the extrusion phase also removes a large amount of water. Therefore, extrusion for obtaining sweet sorghum juice can be considered a pre-processing phase for pyrolysis.

Considering the differences regarding the amount of cellulose, hemicellulose, and lignin found in sweet sorghum plants depending on the soil quality levels, both thermogravimetric analysis (TG) and derivative thermogravimetry (DTG) were performed for both core of the plant and for its outer shell. This is a useful tool to estimate pyrolysis processing temperatures for cases of severely affected crops (which will have a higher share of the total mass of the outer shell, and thus lignin).

The most important parameters determining pyrolysis product yields were tested using laboratory thermo-chemical treatment equipment (a pyrolizer). The fast pyrolysis technique was researched and the main operational parameters were determined, such as heating rate, pyrolysis temperature, and reaction residence time. For a better reflection of the results of industrial pyrolysis equipment, the sample was chosen to contain proportional amounts of leaves, seeds, and stem; no catalysts were used; and the plants were introduced without previous cutting or shredding.

The yield of components in the liquid products was influenced by temperature variations, since different reactions were favored, and therefore some components can be maximized by choosing the right temperature ramps. The identified bio-oil components were classified into the following main chemical groups: alkanes, alkenes, acids, furans, alcohols, phenolic compounds, nitrogen-containing compounds, benzene derivatives, ketones, and PAHs. Marginal soils can produce larger amounts of phenols from lignocellulosic biomass, since these compounds were generated by the decomposition of lignin at the temperature of around $550{ }^{\circ} \mathrm{C}$.

The use of marginal or polluted lands for producing ethanol is a viable option to decrease any perceived competition between the production of food and bioenergy, even though the amount of fuel is lower than that obtained on very fertile lands. The use of marginal lands for bioenergy and chemical production by applying advanced management practices could potentially increase soil carbon sequestration, enhance soil, and water quality, and support ecosystem services.

Marginal land offers the opportunity to practice organic farming, as the soils have not been treated with insecticides, pesticides, or chemical fertilizers due to the low productivity. This would also help restore degraded or marginal arable soils by applying environmentally friendly regenerative technologies, which are equally oriented towards profit and recovery. However, depending on climatic and zonal conditions, it is necessary to assess whether the use of biomass in this way is financially profitable or not. Otherwise, biomass can be integrated into the soil for faster ecosystem regeneration.

Author Contributions: Conceptualization, F.N., M.P. and R.K.; methodology, F.N., M.P., R.K., C.S. and V.N.V.; software, F.N., M.P. and R.K.; validation, C.S., D.C. and V.N.V.; formal analysis, M.P. and R.K.; investigation, F.N., M.P., R.K. and C.S.; resources, C.S., D.C. and V.N.V.; data curation, V.N.V.; writing-original draft preparation, F.N., M.P. and R.K.; writing-review and editing, F.N., M.P., R.K., C.S., D.C. and V.N.V.; visualization, D.C. and V.N.V.; supervision, F.N., D.C. and V.N.V.; project administration, F.N., M.P. and R.K.; funding acquisition, C.S., D.C. and V.N.V. All authors have read and agreed to the published version of the manuscript.

Funding: This research was funded by FSE-European Structural Funds POC-A1-A1.2.3-G-2015, grant number PROVED, ID P_40_301, My SMIS: 105707, Nb. 78/08.09.2016 (2016-2021), and partially by the Academy of Romanian Scientists under financing contracts no 31 and 32/1 October 2021. 
Institutional Review Board Statement: Not applicable.

Informed Consent Statement: Not applicable.

Data Availability Statement: Not applicable.

Conflicts of Interest: The authors declare no conflict of interest.

\section{References}

1. Istrate, I.A.; Cocârţă, D.M.; Wu, Z.; Stoian, M.A. Minimizing Risks from Hydrocarbon Contaminated Soils by Using Electric Field Based Treatment for Soil Remediation. Sustainability 2018, 10, 253. [CrossRef]

2. Di Gruttola, F.; Borello, D. Analysis of the EU Secondary Biomass Availability and Conversion Processes to Produce Advanced Biofuels: Use of Existing Databases for Assessing a Metric Evaluation for the 2025 Perspective. Sustainability 2021, $13,7882$. [CrossRef]

3. Ben, H.; Wu, F.; Wu, Z.; Han, G.; Jiang, W.; Ragauskas, A.J. A Comprehensive Characterization of Pyrolysis Oil from Softwood Barks. Polymers 2019, 11, 1387. [CrossRef] [PubMed]

4. Barry, F.; Sawadogo, M.; Bologo, M.; Ouédraogo, I.W.K.; Dogot, T. Key Barriers to the Adoption of Biomass Gasification in Burkina Faso. Sustainability 2021, 13, 7324. [CrossRef]

5. Yu, J.; Sun, L.; Ma, C.; Qiao, Y.; Yao, H. Thermal degradation of PVC: A review. Waste Manag. 2016, 48, 300-314. [CrossRef] [PubMed]

6. Balat, M. Diesel-like Fuel Obtained by Catalytic Pyrolysis of Waste Engine Oil. Energy Explor. Exploitat. 2008, 26, 197-208. [CrossRef]

7. Nenciu, F.; Vladut, V. Studies on the perspectives of replacing the classic energy plants with Jerusalem artichoke and Sweet Sorghum, analyzing the impact on the conservation of ecosystems. IOP Conf. Ser. Earth Environ. Sci. 2020, 635, 012002. [CrossRef]

8. Persson, H.; Yang, W. Catalytic pyrolysis of demineralized lignocellulosic biomass. Fuel 2019, 252, 200-209. [CrossRef]

9. Bhagia, S.; Akinosho, H.; Ferreira, J.F.S.; Ragauskas, A.J. Biofuel production from Jerusalem artichoke tuber inulins: A review. Biofuel Res. J. 2017, 4, 587-599. [CrossRef]

10. Kang, S.; Post, W.M.; Nichols, J.A.; Wang, D.; West, T.O.; Bandaru, V.; Izaurralde, R.C. Marginal Lands: Concept, Assessment and Management. J. Agric. Sci. 2013, 5, 129-139. [CrossRef]

11. Vincevica-Gaile, Z.; Teppand, T.; Kriipsalu, M.; Krievans, M.; Jani, Y.; Klavins, M.; Hendroko Setyobudi, R.; Grinfelde, I.; Rudovica, V.; Tamm, T.; et al. Towards Sustainable Soil Stabilization in Peatlands: Secondary Raw Materials as an Alternative. Sustainability 2021, 13, 6726. [CrossRef]

12. Strijker, D. Marginal lands in Europe-causes of decline. Basic Appl. Ecol. 2005, 6, 99-106. [CrossRef]

13. Seachinger, T.; Heimlich, R.; Houghton, R.A.; Dong, F.; Elobeid, A.; Fabiosa, J.; Tokgoz, S.; Hayes, D.; Yu, T. Use of U.S. croplands for biofuels increase greenhouse gasses through land-use change. Science 2008, 319, 1238-1240. [CrossRef]

14. Barbier, E.B. Sustaining agriculture on marginal land: A policy framework. Environ. Sci. Policy Sustain. Dev. 1989, 31, 12-40. [CrossRef]

15. Wells, G.R.; Fribourg, H.A.; Schlarbaum, S.E.; Ammons, J.T.; Hodges, D.G. Alternate land uses for marginal soils. J. Soil Water Conserv. 2003, 58, 73-81.

16. Karagöz, S.; Akalın, M.K. Pyrolysis of tobacco residue: Part 1. Thermal. Bioresour. 2011, 6, 1520-1531.

17. United States Department of Agriculture (USDA). Agricultural Conservation Reserve Protection Program (CRP); USDA Farm Service Agency: Washington, DC, USA, 2006.

18. Yaqoob, H.; Teoh, Y.H.; Sher, F.; Jamil, M.A.; Murtaza, D.; Al Qubeissi, M.; UI Hassan, M.; Mujtaba, M.A. Current Status and Potential of Tire Pyrolysis Oil Production as an Alternative Fuel in Developing Countries. Sustainability 2021, 13, 3214. [CrossRef]

19. Food and Agriculture Organization of the United Nations (FAO). Food Insecurity World FAO, The State of Food Security and Nutrition in the World; FAO: Rome, Italy, 2021; ISBN 978-92-5-134325-8. [CrossRef]

20. Lal, R. Carbon sequestration in soils of central Asia. Land Degrad. Dev. 2004, 15, 563-572. [CrossRef]

21. Lăcătuşu, A.R.; Cocârţă, D.M.; Lăcătuşu, R. Ex-situ bioremediation efficiency in removing organic and inorganic compounds from artificially and anthropogenic contaminated soil. Carpathian J. Earth Environ. Sci. 2013, 8, 59-70.

22. Bulmău, C.; Neamțu, S.; Cocârţă, D.M.; Badea, A. Efficiency of PAHs removal from soils contaminated with petroleum products using ex-situ thermal treatments. Rev. Chim. 2013, 64, 1430-1435.

23. Cojocaru, C.; Cocârţă, D.M.; Istrate, I.A.; Creţescu, I. Graphical methodology of global pollution index for the environmental impact assessment using two environmental components. Sustainability 2017, 9, 593. [CrossRef]

24. Carvalhoa, W.S.; Oliveiraa, T.J.; Cardosob, C.R.; Ataíde, C.H. Thermogravimetric analysis and analytical pyrolysis of a variety of lignocellulosic sorghum. Chem. Eng. Res. Des. 2015, 95, 337-345. [CrossRef]

25. Matusiak, M.; Ślęzak, R.; Ledakowicz, S. Thermogravimetric Kinetics of Selected Energy Crops Pyrolysis. Energies 2020, $13,3977$. [CrossRef]

26. Hameed, Z.; Naqvi, S.R.; Naqvi, M.; Ali, I.; Taqvi, S.A.A.; Gao, N.; Hussain, S.A.; Hussain, S. A Comprehensive Review on Thermal Coconversion of Biomass, Sludge, Coal, and Their Blends Using Thermogravimetric Analysis. Hindawi J. Chem. 2020, 2020, 1-23. [CrossRef] 
27. Sarkar, J.K.; Wang, Q. Characterization of Pyrolysis Products and Kinetic Analysis of Waste Jute Stick Biomass. Processes 2020, 8, 837. [CrossRef]

28. Khuenkaeo, N.; Phromphithak, S.; Onsree, T.; Naqvi, S.R.; Tippayawong, N. Production and characterization of bio-oils from fast pyrolysis of tobacco processing wastes in an ablative reactor under vacuum. PLoS ONE 2021, 16, e0254485. [CrossRef]

29. Kaniapan, S.; Hassan, S.; Ya, H.; Patma Nesan, K.; Azeem, M. The Utilisation of Palm Oil and Oil Palm Residues and the Related Challenges as a Sustainable Alternative in Biofuel, Bioenergy, and Transportation Sector: A Review. Sustainability 2021, 13, 3110. [CrossRef]

30. Hu, M.; Chen, Z.; Wang, S.; Guo, D.; Ma, C.; Zhou, Y.; Chen, J.; Laghari, M.; Fazal, S.; Xiao, B. Thermogravimetric kinetics of lignocellulosic biomass slow pyrolysis using distributed activation energy model, Fraser-Suzuki deconvolution, and isoconversional method. Energy Convers. Manag. 2016, 118, 1-11. [CrossRef]

31. Islam, T.; Li, Y.; Cheng, H. Biochars and Engineered Biochars for Water and Soil Remediation: A Review. Sustainability 2021, $13,9932$. [CrossRef]

32. Eibisch, N.; Durner, W.; Bechtold, M.; Fuß, R.; Mikutta, R.; Woche, S.K.; Helfrich, M. Does water repellency of pyrochars and hydrochars counter their positive effects on soil hydraulic properties. Geoderma 2015, 245-246, 31-39. [CrossRef]

33. Kinney, T.J.; Masiello, C.A.; Dugan, B.; Hockaday, W.C.; Dean, M.R.; Zygourakis, K.; Barnes, R.T. Hydrologic properties of biochars produced at different temperatures. Biomass Bioenergy 2012, 41, 34-43. [CrossRef]

34. Cho, D.-W.; Yoon, K.; Ahn, Y.; Sun, Y.; Tsang, D.C.W.; Hou, D.; Ok, Y.S.; Song, H. Fabrication and environmental applications of multifunctional mixed metal-biochar composites (MMBC) from red mud and lignin wastes. J. Hazard. Mater. 2019, 374, 412-419. [CrossRef]

35. Tomczyk, A.; Sokołowska, Z.; Boguta, P. Biochar physicochemical properties: Pyrolysis temperature and feedstock kind effects Rev. Environ. Sci. BioTechnol. 2020, 19, 191-215. [CrossRef]

36. Olugbade, T.O.; Ojo, O.T. Binderless briquetting technology for lignite briquettes: A review. Energy Ecol. Environ. 2020, 6, 69-79. [CrossRef]

37. Olugbade, T.O.; Ojo, O.T. Biomass torrefaction for the production of high-grade solid biofuels: A Review. Bioenergy Res. 2020, 13, 999-1015. [CrossRef]

38. Mathur, S.; Umakanth, A.V.; Tonapi, V.A. Sweet sorghum as biofuel feedstock: Recent advances and available resources. Biotechnol. Biofuels 2017, 10, 146. [CrossRef] [PubMed]

39. Olugbade, T.; Ojo, O.; Mohammed, T. Influence of binders on combustion properties of biomass briquettes: A recent review. Bioenergy Res. 2019, 12, 241-259. [CrossRef]

40. Cardei, P.; Nenciu, F.; Ungureanu, N.; Pruteanu, M.A.; Vlădut, V.; Cujbescu, D.; Găgeanu, I.; Cristea, O.D. Using Statistical Modeling for Assessing Lettuce Crops Contaminated with Zn, Correlating Plants Growth Characteristics with the Soil Contamination Levels. Appl. Sci. 2021, 11, 8261. [CrossRef]

41. Guigou, M.; Lareo, C.; Perez, L.V.; Luberas, M.E. Bioethanol production from sweet sorghum: Evaluation of post-harvest treatments on sugar extraction and fermentation. Biomass Bioenerg. 2011, 35, 3058-3062. [CrossRef]

42. NIST/EPA/NIH Mass Spectral Library with Search Program is the Standard MS Spectra Reference Database. 2020. Available online: https:/ / spectralworks.com/software/nist-ms-msms/ (accessed on 20 December 2021).

43. Bonin Hunt, C.L.; Heaton, E.A.; Cogdill, T.; Moore, K.J. Management of Sweet Sorghum for Biomass Production. Sugar Tech. 2015, 18, 150-159. [CrossRef]

44. Tang, C.; Li, S.; Li, M.; Xie, G.H. Bioethanol Potential of Energy Sorghum Grown on Marginal and Arable Lands. Front. Plant Sci. 2018, 9, 440. [CrossRef]

45. Bartzialis, D.; Giannoulis, K.D.; Skoufogianni, E.; Lavdis, A.; Zalaoras, G.; Charvalas, G.; Danalatos, N.G. Sorghum dry biomass yield for solid bio-fuel production affected by different N-fertilization rates. Agron. Res. 2020, 18, 1147-1153. [CrossRef]

46. Zhang, F.; Wang, Y.; Yu, H.; Zhu, K.; Zhang, Z.; Zou, F.L.J. Effect of excessive soil moisture stress on sweet sorghum: Physiological changes and productivity. Pak. J. Bot. 2016, 48, 1-9.

47. Zhao, Y.L.; Dolat, A.; Steinberger, Y.; Wang, X.; Osman, A.; Xie, G.H. Biomass yield and changes in chemical composition of sweet sorghum cultivars grown for biofuel. Field Crops Res. 2009, 111, 55-64. [CrossRef]

48. Mircea, C.; Nenciu, F.; Vlădut, V.; Voicu, G.; Cujbescu, D.; Gageanu, I.; Voicea, I. Increasing the performance of cylindrical separators for cereal cleaning, by using an inner helical coil. INMATEH Agric. Eng. 2020, 62, 249-258. [CrossRef]

49. Lopez-Sandin, I.; Gutiérrez-Soto, G.; Gutiérrez-Díez, A.; Medina-Herrera, N.; Gutiérrez-Castorena, E.; Galicia-Juárez, M.; Zavala-García, F. Biomass and sugar production dynamics in sweet sorghum variety Roger. Chil. J. Agric. Res. 2021, 81, 92-101. [CrossRef] 